\title{
PRECISION ATTACHMENTS; APPLICATIONS AND LIMITATIONS
}

Prabhakar B. Angadi, Meena Aras, Cecil Williams, Suresh Nagaral
1. Senior Lecturer, Department of Prosthodontics, Daswani Dental College and Research Centre, Ranpur, Kota, Rajasthan
2. Professor and Head, Department of Prosthodontics, Goa Dental College and Hospital, Bambolim, Goa 3. Professor and Head, Department of Prosthodontics, Daswani Dental College and research centre, Ranpur,
Kota, Rajasthan.
4. Senior lecturer, ACPM Dental College, Dhule, Maharashtra .

\section{CORRESPONDING AUTHOR}

Dr. Prabhakar Angadi,

Senior Lecturer, Department of Prosthodontics,

Daswani Dental College and Research Centre,

Ranpur, Kota, Rajasthan. 325003

E-mail: drprabhakar_angadi@yahoo.co.in

Ph: 00917891287907.

ABSTRACT: A unique concern of a removable denture when compared to others is retention. Retention is the ability of the prosthesis to resist the movement of denture away from the supporting tissues/teeth. The component of removable denture which provides retention is called as direct retainer. 1,3,4

A direct retainer can be either an extracoronal or intracoronal retainer. Extracoronal direct retainer uses mechanical resistance to displacement through components placed on external surface of abutment teeth. Intracoronal retainer is either cast or attached totally within the restored natural contours of an abutment tooth. ${ }^{1}$

One of the main drawbacks of extracoronal retainers used in partial dentures is visibility. Many patients find themselves in an aesthetically compromised state when these retainers are placed on teeth in visible area. Precision attachments provide solution for this problem. Also, precision attachments provide better vertical support and better stimulation to the underlying tissue through intermittent vertical massage..$^{1,9}$

Although the history of intracoronal retainers goes back to $5^{\text {th }}$ and $4^{\text {th }}$ centuries $\mathrm{BC}$, technically more sound developments began in early $20^{\text {th }}$ century AD, with Dr. Herman E. S. Chayes formulating the principle of internal attachment in 1906. Since then precision attachments are playing an important role in removable and fixed partial denture, conventional and implant supported overdenture. ${ }^{9}$

KEY WORDS: Precision attachment, internal attachment, parallel attachment, frictional attachment.

INTRODUCTION: Precision attachment can be described as a retainer used in fixed and removable partial denture construction consisting of a metal receptacle and a closely fitting part, the former is usually contained within the normal or expanded contours of the crown of the abutment tooth, and the latter is attached to a pontic or to the denture frame work. ${ }^{1}$

SYNONYMS: Internal attachment, parallel attachment, frictional attachment, key and key way attachment, slotted attachment.

\section{INDICATIONS AND CONTRA INDICATIONS 1-11 INDICATIONS:}


Movable joints in fixed movable bridge work.

As stress breaker in free end saddles and bridges.

Intracoronal attachments as effective direct retainers for removable partial dentures.

As a connector for sectional dentures.

Sections of a fixed prosthesis may be connected with intra coronal attachments.

To lock a connector joining saddles in the opposite side of the arch.

As contingency devices for the extension or conversion of existing dentures.

Where fixed dentures are contraindicated due to periodontal condition.

In the esthetic zone where extracoronal direct retainer adversely affects the esthetics.

To retain hybrid dentures.

\section{CONTRAINDICATIONS:}

1. In patients who are sick and the senile (prosthesis with attachments must be inserted along one precise path of insertion, the patient must posses an average degree of manual skill).

2. Patients with severe Periodontisis.

3. Patients with abnormally high caries rate.

4. Where there is inadequate space (Teeth that are very narrow facio-lingually).

\section{ADVANTAGES AND DISADVANTAGES ${ }^{1-11}$}

\section{ADVANTAGES:}

1. The labial or buccal clasp arms can be eliminated altogether. This makes spectacular improvement in the esthetic excellence of a denture especially in the maxillary arch.

2. Precision attachments are less stressful to the abutment teeth than conventional clasps.

\section{DISADVANTAGES:}

1. The tooth may have to be extensively prepared to provide required space to accommodate intracoronal attachment.

2. The attachment is subject to wear as a result of friction between metal parts. As wear occurs, male portion fits more loosely thus permitting excessive movement and threat of injury to abutment teeth.

3. The extra coronal type of retainer extends out from the tooth near the gingival border, so there may be gingival irritation followed by usual inflammatory sequel.

4. The extracoronal type of attachment must occupy the space immediately adjacent to abutment tooth, which is precisely where a replacement tooth should ideally be positioned.

SEMIPRECISION 9 :While prefabricated attachments are called as precision attachments, those fabricated in laboratory are called as semiprecision attachments. Precision attachment is made of precious metal and fit of two working elements is machined to very close tolerances, hence is more precise than laboratory fabricated attachment. Semiprecision attachments are usually 
fabricated in base metal alloys. The semiprecision attachment is also called as precision rest, milled rest or the internal rest.

\section{CLASSIFICATIONS $2,3,9,10,13-15$}

A simple classification based on location and attachment shape is presented here.

\section{INTRACORONAL ATTACHMENTS:}

The two parts of an intracoronal attachment consist of a flange and a slot. The flange is joined to one section of the prosthesis and the slot unit embedded in a restoration forming part of another section of the prosthesis.

Two types of intracoronal attachments are available

\section{a. Those whose retention is entirely frictional}

E.g. McCollum intra coronal unit.

b. Those whose retention is augmented by a mechanical lock.

E.g. Schatzmann unit

Additional retention is provided by a spring loaded plunger.

Depending on the cross sections intra coronal attachments can be classified into (Fig- 1)

1. H-Shaped flanges The external frictional flange of H-Shaped unit strengthens the attachment, without increasing the size of the female part.

\section{T-shaped flanges}

E.g. Chayes attachment.

3. Attachments with a circular cross section. They are suitable only for joining two sections of a fixed prosthesis.

The friction fit intracoronal attachments with adjustment potential are:
a. Chayes
b. Crismani attachments
c. McCollum unit
d. Ancra attachment.
e. T-Geschiebe 123

\section{ATTACHMENTS WITH AUXILIARY RETENTIVE FEATURES:}

Auxiliary retentive features are incorporated in some attachments in an effort to provide more retention for a given frictional area although no extra stability is provided. A minimum of $4 \mathrm{~mm}$ vertical space is necessary.

E.g.: Crismani units, Stern gingival latch attachment and Micro.

Before choosing an attachment with auxiliary retentive devices the following factors should be considered.
a. Bulk
b. Adjustment
c. Retention mechanism
d. Trimming the attachment 
e. Plaque control

THE FRICTION FIT INTRACORONAL ATTACHMENTS WITHOUT ADJUSTMENT POTENTIAL: Lack of adjustment potential renders this type of unit unsuitable for removable prosthesis, as repeated insertion and removal will cause the attachment to wear. They are useful for joining a series of crowns without a common path of insertion. Round profiles are useful when anterior teeth are concerned.

E.g.: Beyler.

\section{Applications of intracoronal attachments}

1. Retainers: Intra coronal attachments are effective and almost invisible retainer for bilateral and unilateral prostheses.

2. Connectors: Sections of a fixed prosthesis may be joined with intracoronal attachments. This possibility can be useful where;

a. Prostheses do not share a common path of insertion yet can be connected rigidly in the mouth.

b. The operator prefers to limit the length of individual castings while making a large span fixed prosthesis.

c. The prognosis of a distal abutment is dubious.

Connecting the posterior segment with an attachment allows subsequent removal without damage to the main restoration. The attachment slot can be used for later construction of an attachment retained denture

\section{EXTRACORONAL ATTACHMENTS:}

These attachments have part or all of their mechanism outside the crown of a tooth. Many of these units allow a certain amount of movement between the two sections of the prosthesis. Their main application is for distal extension prosthesis. They may be used to retain restorations for bounded spaces. Extracoronal attachments can be subdivided into following groups.

\section{a. Projection units}

The units are attached to the proximal surface of a crown. These groups can be divided in turn into;

1. Those that provide a rigid connection. Eg. Conex attachment

2. Those that allow play between the components. Eg. Dalbo extracoronal projection unit, Ceka system with retaining ring.

\section{b. Connectors}

These units connect two sections of a removable prosthesis and allow a certain degree of play. Two basic types of joints are manufactured

1. The axial rotation joint: It provides restricted vertical travel together with predetermined hinge movement. A small window is cut out of the female section around the screw. The male section is therefore free to travel up and down within the narrow confine of the window. Rotation and lateral movements can be provided by dismantling 
the attachment and very slightly trimming the male unit. This joint can be incorporated within the Scott attachment.

2. The rotation joint: Here there is no window around the screw and therefore vertical movements cannot take place. The rotation joint was designed for unilateral distal extension prosthesis as this type of denture is usually tooth and mucosal supported on one side and entirely tooth supported on the opposite side. Since vertical movement could be damaging to the teeth on the tooth supported side, Steiger designed the rotation joint to allow only slight rotational and lateral movements in order to minimize torque transmitted from the distal extension prosthesis. The design would therefore incorporate an axial rotation joint connecting the distal extension base to the retainer and major connector, while the retainer on the opposite, tooth supported, side would be connected through a rotation joint. The Steiger joints are models of careful designs and are one of the few attachments in which the amount and direction of the movement allowance can be precisely determined by the operator. If appreciable wear takes place, both parts of the attachment can be removed from the mouth and a replacement soldered on.

\section{STUD ATTACHMENT (Figure 2):}

These attachments are so called because of the shape of the male units that are usually soldered to the diaphragm of a post crown. The female part fits over the male unit and is embedded within the acrylic resin of the prosthesis or soldered to a metal substructure. There are a few systems in which the male section forms parts of the denture and the female part of the root surface preparation. Few stud attachments are entirely rigid, since their size makes it difficult to prevent a small amount of movement between the two components. In some attachments springs or other devices are specifically incorporated to allow a controlled degree of movement. Dalbo, Conod's unit, Rothermann unit, Baer and Fah units are few examples of stud attachments.

Stud attachments have numerous applications:

1. Overdenture being relatively small they can provide additional stability, retention and support while the positive lock of certain units can maintain the border seal of the denture.

2. Non-vital partial denture abutments. The loads applied in these circumstances can be considerable, so one of the larger and stronger units is recommended.

3. For retention of a small tooth supported restoration with non-vital abutment.

\section{BAR ATTACHMENTS (Figure 3)}

Bar attachments consist of a bar spanning an edentulous area joining together teeth or roots. The denture fits over the bar and is connected to it with one or more sleeves. Bar attachments are of 2 categories.

a. Bar joints These units allow play between denture and bar. The bar is usually attached to diaphragms on root filled teeth, locking the roots together and improving the crown / root ratio. A common path of insertion for the retaining posts is desirable although divergence can be overcome by mechanical means. Alternatively the abutment teeth can be crowned and these crowns connected by the bar. 


\section{Bar joints can be subdivided into:}

\section{Single sleeve bar joints}

The Dolder bar joint is an excellent example of this attachment. This well tried bar is produced from wrought wire, pear shaped in cross section and running just in contact with the oral mucosa between the abutments. An open sided sleeve is built into the impression surface of the denture and engages the bar when the denture is inserted.

\section{Multiple sleeve joints}

If several short sleeves are substituted for the continuous one, there is no need for the bar to run straight and it can be bent to follow the vertical contours as well as the antero-posterior curvature of the ridge.

Gilmore, Ackerman, Hader are few commonly used bar joints. Multiple sleeve bar joints are more versatile than the single sleeve units, but the bars seem to have slightly less rigidity.

\section{b. Bar units}

Bar units are comparatively rigid allowing no movement between the sleeve and bar. Although some load may be distributed to the mucosa these prostheses are mainly tooth borne. Bar units may be useful where;

1. There are 4 or more abutment teeth and large edentulous spaces.

2. The number and distribution of the teeth does not allow construction of a satisfactory clasp retained partial denture.

3. There are edentulous areas with considerable resorption.

4. Rigid splinting is required for remaining teeth or roots.

Bar units provide excellent retention and stability for a denture while rigidly splinting the abutments. Artificial mucosa can be provided by the denture flange and the removable section can be rebased or repaired like clasp retained prosthesis.

Drawbacks are that the bar provides a medium for accumulation of plaque and the patient must maintain a good standard of hygiene. Other contra indications are patients with poor manual skills and those with limited vertical or bucco lingual space.

The Dolder bar unit is a well established and reliable unit. The bar has parallel sides unlike the pear shaped profile of the bar joint. Retention for the sleeve is entirely frictional, provided by the parallel vertical surfaces of both sections.

M.P. CHANNEL SYSTEM: These MP channels are extremely slim and save the operator and technician the problems and expense of milling. Additional retention between the two sections of the unit can be provided by incorporating a plunger in the sleeve. Guiding flanges should be incorporated to prevent rotation around the plunger and to obtain maximum retention.

MECHANISM OF ACTION: Retainers must hold the prosthesis securely in place during chewing, swallowing, speaking and other oral functions. Therefore, male and female portions must fit together precisely.

Resistance to separation within the attachment is by following mechanisms. 

i) Friction
ii) Binding
iii) Wedging of conical bodies
iv) Internal spring loading
v) Active Retention

ATTACHMENT SELECTION: In 1971, 126 attachments were listed and classified by Dr. Merrill Mensor; this is called as E. M. attachment selector. ${ }^{15}$

It has 5 charts giving specification as to type, vertical dimension (Minimal and Maximal), whether it is for anterior and posterior teeth, whether the assembly is simple or complex, whether the function is rigid or resilient, type of resilience, size of movement and type of retention. It shows if the attachment is interchangeable or replaceable and finally what type of alloy and material it is made of.

E.M. attachment selector system utilizes a colour coded millimeter attachment gauge to define the vertical clearance available in the edentulous regions of occluded casts for attachment selection. The gauge is made of plastic and measuring $75 \mathrm{~mm}$ in length. It is graduated from 3 to $8 \mathrm{~mm}$ in $1 \mathrm{~mm}$ increments with a corresponding colour code. Red designates 3 to $4 \mathrm{~mm}$, yellow designates 5 to $6 \mathrm{~mm}$ and black designates 7 to $8 \mathrm{~mm}$. The gauge is placed between the occluded casts adjacent to a tooth that will carry an attachment. The measurement is thus read numerically and according to colour. The vertical limits measured by the EM gauge are the common area of concern for all connector systems. The available space will govern the type of attachment system that can be used. A closed vertical space will narrow the selection of available or recommended attachments. Where vertical intermaxillary space is abundant, the choice of attachment systems is less restricting.

In selecting an attachment system;

i) The first decision that must be made is whether to use an intracoronal or extracoronal attachment

ii) The second decision to be made is whether to use a resilient or a nonresilient type

iii) The third consideration is that the largest attachment can be used within the given space should be chosen to gain maximum stability, retention and strength for the prosthesis.

CONCLUSION: The success of prosthesis depends on careful treatment planning and attention to the prosthodontic problems; the mechanical ingenuity of the attachment is important, but must take second place. Precision attachments present a challenge in the technical skill. A thorough understanding of the biomechanics of maxillomandibular function, different attachments and knowledge of material science is essential in treating a case of precision attachment. Unfortunately, most often precision attachments are chosen from descriptions in manufacturer's catalogues which leads to failure of precision attachment cases. Precision attachments serve the function of retention, stress distribution and aesthetics successfully provided the case is planned based on sound biological and technical grounds and proper care is rendered by the dentist and the patient during the maintenance phase.

\section{REFERENCES:}

1. Rudd KD, Morrow RM, Eissmann HF - Dental Laboratory Procedures - Removable Partial Dentures. St. Louis, Missouri: CV Mosby; 1986. 
2. Carr AB, McGivney GP, Brown DT. McCracken's Removable Partial Prosthodontics. 11th ed. St. Louis, Missouri: Elsevier Mosby; 2005.

3. Misch CE. Dental Implant Prosthetics. St. Louis, Missouri: Elsevier Mosby; 2005.

4. Stewart KL, Rudd KD, Kuebkar WA. Clinical Removable Partial Prosthodontics. 2nd ed. St. Louis, Missouri: CV Mosby; 1986

5. Miller EL, Grasso JE. Removable Partial Prosthodontics. Baltimore, U.S.A: Williams and Wilkins; 1979.

6. Malone WFP, Koth DL. Tylman's Theory and Practice of Fixed Prosthodontics 8th ed. Chennai, India: All India publishers and distributors; 1997.

7. Roberts DH. Fixed Bridge Prostheses. 2nd ed. Bristol, England: John Wright and sons; 1980.

8. The academy of prosthodontics. Glossory of prosthodontic terms. 8th ed J Prosthet Dent $2005 ; 40$.

9. Graber G. Colour Atlas of Dental Medicine vol 2 Removable Partial Dentures. Stuttgart, Germany: Georg Thieme Verlag; 1988.

10. Preiskel HW. Precision Attachments in Dentistry. 3rd ed. London: Henry Kimpton; 1979.

11. Rhoads JE, Rudd KD, Morrow RM. Dental Laboratory Procedures-Fixed Partial Dentures. St. Louis, Missouri: CV Mosby; 1986.

12. Barclay CW, Walmsley AD. Fixed and Removable Prosthodontics. Colour guide. Edinburgh: Churchill Livingstone; 1998.

13. Preiskel HW. Overdentures Made Easy. A Guide to Implant and Root Supported Prostheses. London, UK: Quintessence Publising; 1996.

14. Ray GE, Alexander AG, Precision Attachments. 2 nd ed.

15. Mensor MC. Classification and selection of attachments. J Prosthet Dent 1973; 29: 494-97.
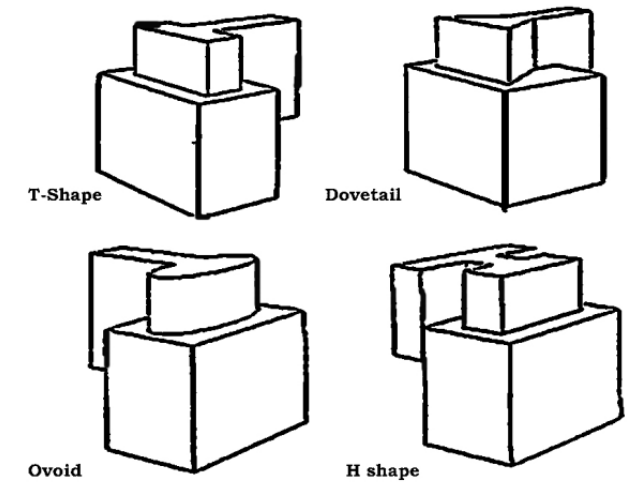

Figure 1 Cross sections of attachments 


\section{REVIEW ARTICLE}

\section{Stud attachment (Dalbo)}

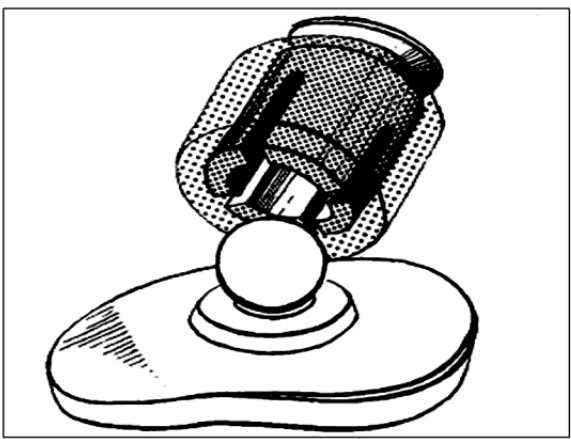

Figure. 2 Stud attachment

Bar attachment (Dolder)

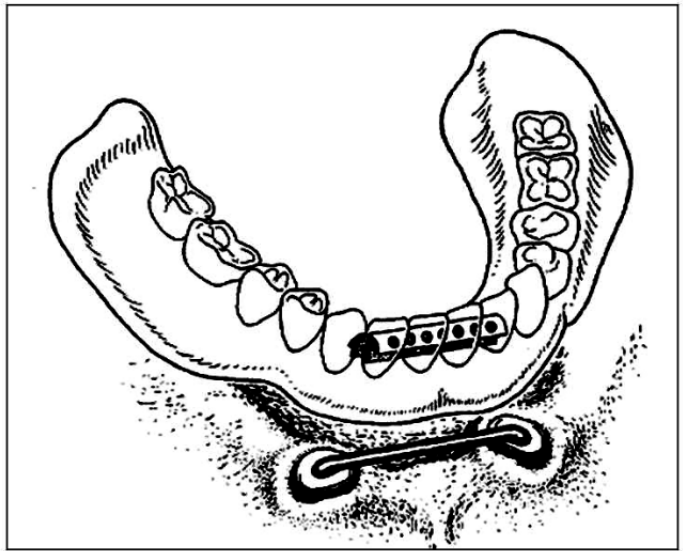

Figure 3 Bar attachment 